\title{
Changes in Gene Expression During the Formation of Bioengineered Heart Muscle
}

\author{
Luda Khait and Ravi K. Birla
}

Section of Cardiac Surgery, University of Michigan, Ann Arbor, MI, USA

\begin{abstract}
A three-dimensional bioengineered heart muscle (BEHM) construct model had been previously developed, exhibiting contractile forces up to $800 \mu \mathrm{N}$. The interest of this study was to determine gene expression levels of biologic markers involved in calcium-handling between BEHM, cell monolayer, and neonatal heart. Cardiac cells were isolated from one litter of F344 rats and organized into groups $(n=5)$ : 4-, 7-, 10-day BEHM and cell monolayer; BEHM was evaluated for cell viability and contractility. Groups were then analyzed for mRNA expression of calcium-handling proteins: myosin heavy chain (MHC) $\alpha$ and $\beta$, Sarcoplasmic reticulum $\mathrm{Ca}++$ ATPase (SERCA) 2, phospholamban (PBL), and ryanodine receptor. BEHM exhibited electrically stimulated active force $(208 \pm 12 \mu \mathrm{N}$ day $4,361 \pm 22 \mu \mathrm{N}$ day 7 , and $344 \pm 29 \mu \mathrm{N}$ day 10$)$ and no decrease in cell number. Real-time polymerase chain reaction (PCR) showed an increase in gene expression of all
\end{abstract}

calcium-handling proteins in BEHM at 7 and 10 days compared with monolayers, for example, comparing BEHM to monolayer ( 7 and 10 days, respectively), MHC- $\alpha$ : 2600-fold increase and a 100-fold increase; MHC- $\beta$ : 70 -fold increase at 10 days; ryanodine receptor: 74-fold increase at 10 days; SERCA: 19-fold increase and sixfold increase; PBL: 158fold increase and 24-fold increase. It was concluded that a three-dimensional environment is a better culturing condition of cardiac cells than a monolayer. Also, BEHM constructs demonstrated a high similarity to a native myocardium, and is, thus, a good starting foundation for engineered heart muscle. Key Words: Real-time polymerase chain reaction-Tissue engineering-Cardiac myocytesFibrinogen/fibrin-Active force-Myosin heavy chain - Sarcoplasmic reticulum Ca++ ATPase-Phospholamban -Three-dimensional heart muscle.
In the past 50 years, successful transplantation of organs has included the kidney, liver, heart, lungs, pancreas, and small intestines (1). Although organ transplantation seems like a feasible treatment, there are many problems associated with this process. Primarily, the number of patients awaiting an organ transplant drastically exceeds the amount of organs available. Another important factor is the postoperative lifestyle of patients after organ transplantation. These patients have a high risk of developing infections or possibly an immune response against their new organ (1). Because organ availability is so limited, a new field called tissue engineering has evolved and exploded in the last several decades as a possible alternative means of treatment for end-stage organ or

doi:10.1111/j.1525-1594.2008.00669.x

Received May 2007; revised February 2008.

Address correspondence and reprint requests to Dr. Ravi K. Birla, Biomedical Science Research Building, 109 Zina Pitcher Place, Rm. 2018, Ann Arbor, MI 48109-2200, USA. E-mail: rbirla@ umich.edu tissue failure. The field itself is defined as "devices or processes that (i) combine living cells and biomaterials; (ii) utilize living cells as therapeutic or diagnostic reagents; (iii) generate tissues or organs in vitro for subsequent implantation; and/or (iv) provide materials or technology to enable such approaches" (2).

The focus of this study was designed around cardiac tissue engineering. It is estimated that approximately 5 million Americans are suffering from congestive heart failure, and 400000 patients are newly diagnosed each year, making this disease the leading cause of death (3). To be able to engineer a three-dimensional heart muscle from a patient's cells and use it as a patch on the failing myocardium is the ultimate application goal of cardiac tissue engineering (3). Several approaches to engineer cardiac tissue in vitro, such as synthetic scaffolds (4), biodegradable gels (5-7), and self-organization strategies, have been evaluated and utilized.

A method previously described, with $100 \%$ success rate, included the utilization of rapidly degrading fibrin gel to develop functional cardiac muscle in 
vitro using two different approaches: layering and embedding neonatal cardiac myocytes (8). Up to $800 \mu \mathrm{N}$ of active force was generated using the layering approach and validated the cell presence within the fibrin gel matrix via histological evaluation (8). Although these models exhibited spontaneous contractile properties, the biologic aspects of the constructs have not yet been examined.

An important pathway that controls the rate and force of relaxation and contractile properties of cardiac muscle is the calcium-handling pathway within cardiac myocytes. Briefly, depolarization of the sarcolemmal membrane in a cardiac muscle cell activates calcium channels in the cell membrane and sarcoplasmic reticulum (SR), via ryanodine receptor (RyR) stimulation, which allows an influx of calcium from the extracellular space as well as the SR, inducing muscle contraction (9). Next, calcium ions are quickly recycled back to the SR through a calcium ATPase of the SR (Sarcoplasmic reticulum $\mathrm{Ca}++$ ATPase [SERCA] 2) channel, resulting in muscle relaxation (10). In turn, SERCA 2 is regulated by the phosphorylation state of phospholamban (PBL), an integral membrane protein that is colocalized with SERCA 2 (11). It has also been demonstrated to interact directly with SERCA 2 (12). When PBL is phosphorylated, it dissociates from SERCA 2 and allows for the calcium transport into the SR by SERCA 2 (10) by increase in affinity of calcium to SERCA $2(13,14)$. Dephosphorylation of PBL results in inhibition of SERCA 2 and a slower reuptake of calcium back into the SR.

Calcium influx induces muscle contraction through the myosin-actin interaction. Myosin is abundant in skeletal and heart muscle and is responsible for energy transduction and force production $(15,16)$. Two myosin isoforms are predominant in the cardiac muscle: myosin heavy chain $\alpha$ (MHC- $\alpha$ ) and myosin heavy chain $\beta$ (MHC- $\beta$ ). It has been reported that the speed of contractions in different species are correlated with the variation in the MHC- $\alpha / \mathrm{MHC}-\beta$ ratio (17) due to electrophoretic activity and ATPase activity (18). Therefore, it can be concluded that fastcontracting ventricles of mice and rats contain predominantly the MHC- $\alpha$ isoform, whereas the slow-contracting ventricles of humans and bovine contain predominantly the MHC- $\beta$ isoform. The ratio of these two isoforms is variable during postnatal life, as gene expression fluctuates in response to hormones, changes in cardiac workload, and aging (19).

In the current study, the primary interest was to analyze the molecular profile of the bioengineered heart muscle (BEHM) constructs previously developed. The generation of up to $800 \mu \mathrm{N}$ of force was the motive behind observing gene expression of various calcium-handling markers described above. Using a neonatal rat heart as a control, the levels of gene expression between these hearts and BEHM constructs at various time points during development were compared. Also, gene expression of cardiac cells cultured as a two-dimensional monolayer was observed in order to determine differences of culturing conditions. As a starting point for the current study, five genes that are known to have a profound impact on cardiac muscle physiology were selected: MHC- $\alpha$, MHC- $\beta$, SERCA2, PLB, and RyR. Knowing if the BEHM constructs produce a similar level of calcium-handling protein mRNA as a neonatal heart will provide a biologic foundation to continue to develop a stronger and more functional BEHM.

\section{METHODS}

National Institute of Health (NIH) guidelines for the care and use of laboratory animals (NIH Publication \#85-23 Rev. 1985) have been observed. All materials were purchased from Sigma (St. Louis, MO, USA) unless otherwise specified.

\section{Isolation of neonatal cardiac myocytes}

Cardiac myocytes were isolated from the hearts of one litter of 2- to 3-day-old F344 rats using an established method (20). The hearts were cut into fine pieces and suspended in a dissociation solution (DS) that consisted of $0.32 \mathrm{mg} / \mathrm{mL}$ collagenase type II (Worthington Biochemical Corporation, Lakewood, NJ, USA) and $0.6 \mathrm{mg} / \mathrm{mL}$ pancreatin dissolved in a buffer consisting of $116 \mathrm{mM} \mathrm{NaCl}, 20 \mathrm{mM}$ HEPES, $1 \mathrm{mM} \mathrm{Na}_{2} \mathrm{HPO}_{4}, 5.5 \mathrm{mM}$ glucose, $5.4 \mathrm{mM} \mathrm{KCl}$, and $0.8 \mathrm{mM} \mathrm{MgSO}_{4}$. Digestion was carried out in an orbital shaker for $5 \mathrm{~min}$ at $37^{\circ} \mathrm{C}$, after which the supernatant was replaced with fresh DS and the digestion process was continued for an additional $90 \mathrm{~min}$. At $45 \mathrm{~min}$, the hearts were further dissociated using a pipette and then placed back into the orbital shaker for the other $45 \mathrm{~min}$. At the end of the digestion process, the supernatant was collected, the same amount of culture medium (CM) was added, consisting of $330 \mathrm{~mL}$ M199, $100 \mathrm{~mL}$ F12K, $40 \mathrm{~mL}$ fetal bovine serum, $40 \mathrm{~mL}$ calf bovine serum, $5 \mathrm{~mL}$ antibiotic-antimycotic, $40 \mathrm{ng} / \mathrm{mL}$ hydrocortisone, $30 \mu \mathrm{g} / \mathrm{mL}$ ascorbic acid, $0.5 \mathrm{mM}$ plasma inhibitor, centrifuged at $1500 \mathrm{rpm}$ for $5 \mathrm{~min}$, and the cell pellet was resuspended in $10 \mathrm{~mL}$ of $\mathrm{CM}$. The cells were then counted using a hemacytometer. Based on preliminary experimentation, it was found that increasing the cell purity by preplating had resulted in a decrease in active twitch force (manuscript under 


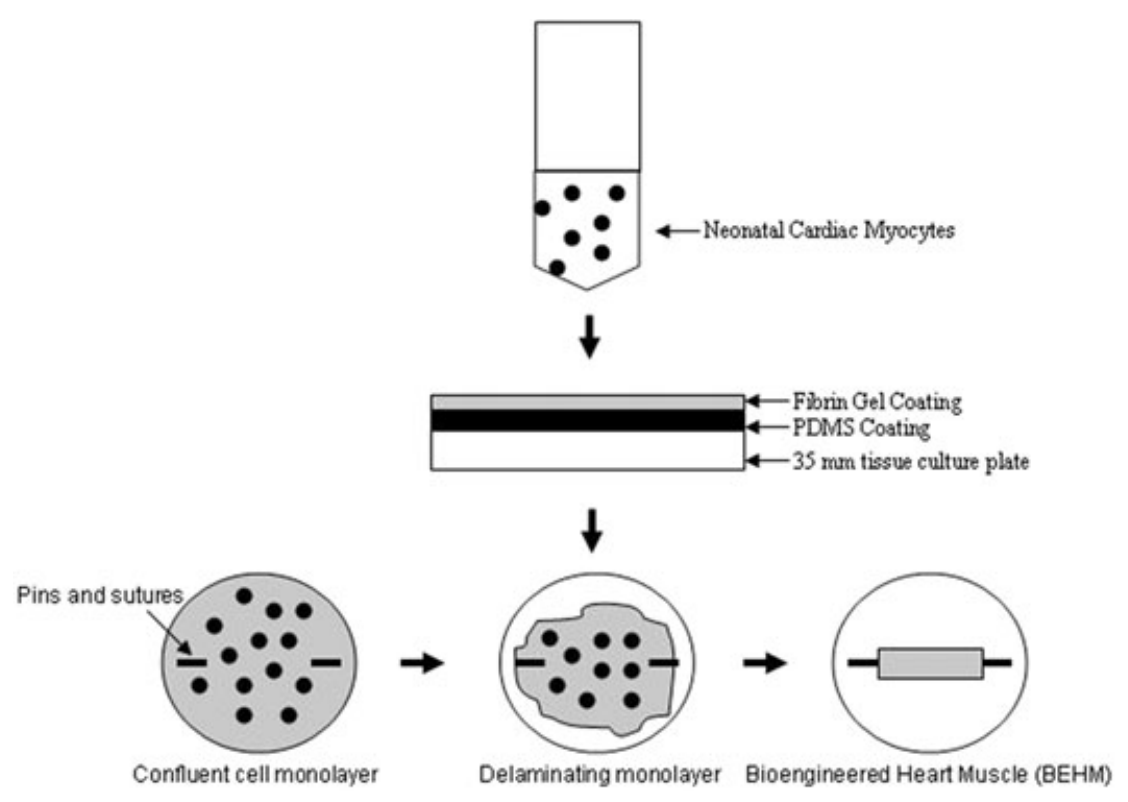

FIG. 1. Methods for formation of threedimensional BEHM are shown. First, a layer of PDMS is coated onto a 35-mm cell culture dish, followed by a fibrin gel. Next, $1 \times 10^{6}$ neonatal cardiac cells are plated on top of the fibrin gel and allowed to distribute evenly. Several days postplating, cardiac myocytes begin to spontaneously contract, pulling on the fibrin gel. As a result, the fibrin gel, along with the myocytes, begins to delaminate toward the middle of the plate and form a threedimenstional construct anchored at either end with anchor points placed previously. preparation). Also, it was determined that the percentage of cardiomyocytes is approximately $40 \%$, comparable with $70 \%$ found in normal mammalian tissue (R.K. Birla, unpublished results).

\section{Preparation of the plates}

The detailed method for preparing the culture surface for engineering skeletal muscle has been described in detail $(21,22)$. This procedure was modified to engineer cardiac muscle (23). Briefly, 35-mm culture plates were coated with $1.5 \mathrm{~mL}$ of a polydimethylsiloxane (PDMS) elastomer (Dow Chemical Corporation, Midland, MI, USA). Anchor points were 6-mm-long segments of size 0 braided silk sutures (Ethicon, Cornelia, GA, USA) pinned $12 \mathrm{~mm}$ apart in the center of the culture surface.

\section{Formation of fibrin gel and cell plating}

$500 \mu \mathrm{L} \mathrm{CM}$ containing $10 \mathrm{U} / \mathrm{mL}$ thrombin was plated on the surface of $35-\mathrm{mm}$ cell culture plates coated with SYLGARD (PDMS, type 184 silicone elastomer, World Precision Inc., Sarasota, FL, USA). After this, $200 \mu \mathrm{L}$ of $20 \mathrm{mg} / \mathrm{mL}$ fibrinogen was added to the $35-\mathrm{mm}$ plate. The solution was mixed to promote the formation of a fibrin gel within $10-15 \mathrm{~min}$ in an incubator at $37^{\circ} \mathrm{C}$. Primary cardiac cells were diluted in $\mathrm{CM}$ and plated at 1 million cells in $2 \mathrm{~mL}$ of $\mathrm{CM} / 35-\mathrm{mm}$ plate after complete gel formation. The cells were cultured in an incubator at $37^{\circ} \mathrm{C}$ and $5 \% \mathrm{CO}_{2}$ with medium changes every second day. Ten $35-\mathrm{mm}$ cell culture dishes were also plated with 1 million cells in $2 \mathrm{~mL}$ of $\mathrm{CM}$ without SYLGARD coating and fibrin gel (Fig. 1).

\section{Experimental design}

One heart from a 2- to 3-day-old neonatal rat pup was frozen in liquid nitrogen immediately postremoval for RNA isolation. The rest were processed to isolate primary cardiac myocytes for plating on a fibrin gel in a $35-\mathrm{mm}$ culture dish. Just prior to plating, 5 million cells from the cell suspension were taken out and processed for RNA isolation. The remainder of the cells were then divided into six groups, with fix plates per group: 4-day cell monolayer, 7-day cell monolayer, 10-day monolayer, 4-day BEHM, 7-day BEHM, 10-day BEHM. At each designated day, the cells/BEHMs were analyzed for total RNA content, cell viability, active force, and specific force. Extraction of total RNA from the 4-day BEHM was unsuccessful due to the high gel content compared with the total cell number embedded. Thus, the corresponding 4-day cell monolayer was also not analyzed for mRNA expression. The constructs were frozen in liquid nitrogen prior to RNA isolation and stored at $-80^{\circ} \mathrm{C}$ until processing (Fig. 2).

\section{Cell viability}

To test the cell viability at each point of BEHM formation, a WST-1 assay protocol (Roche Applied Science, Indianapolis, IN, USA) was used. Briefly, $100 \mu \mathrm{L}$ of WST-1 solution was added to culture dishes containing cells and $2 \mathrm{~mL}$ of media. After an overnight incubation, absorbance was read on a standard plate reader at $485 \mathrm{~nm}$ and compared with a standard curve. The incubation time was optimized in prior pilot studies. 


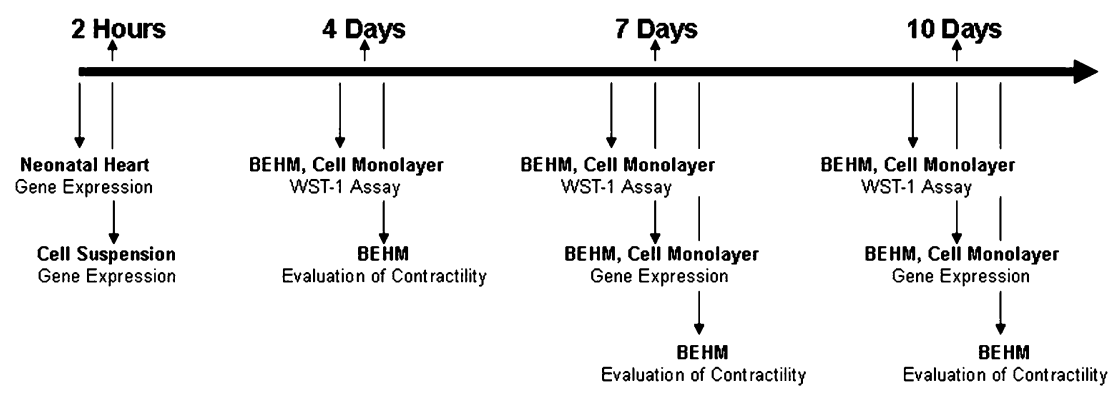

FIG. 2. The experimental design used in this study is shown. At each time point, samples were evaluated for the appropriate evaluation, including cell viability, contractile properties, and gene expression.

\section{Evaluation of contraction}

The method for evaluating the contractility of engineered skeletal and cardiac muscle has been described in detail (23). This method was modified slightly. Briefly, the BEHM was placed in $\mathrm{CM}$ at $37^{\circ} \mathrm{C}$ between parallel platinum electrodes. One end was fixed to the plate and the other end was attached to a custom-built optical force transducer. Stimulated active force (response to a single electrical impulse) measurements were then recorded at $25 \mathrm{~V}$ and a 10-ms pulse width. Each BEHM was electrically stimulated five times, with the average taken. Additionally, spontaneous contractile force was recorded for each construct. The cross-sectional area of the BEHMs was calculated from the construct diameter, which was determined by a calibrated eyepiece reticle with a resolution of $5 \mu \mathrm{m}$. The construct was assumed to be cylindrical for this calculation. The specific force $\left(\mathrm{kN} / \mathrm{m}^{2}\right)$ of each BEHM was determined by normalizing the stimulated twitch force to the total cross-sectional area. Initial stimulation parameters were selected based on previous experience with engineered cardiac muscle constructs. The stimulation parameters had been optimized for this system in pilot experiments.

\section{RNA isolation}

All BEHM constructs and neonatal heart were stored in a $-80^{\circ} \mathrm{C}$ freezer. RNA isolation was performed using the Qiagen RNeasy Mini kit (Qiagen Inc., Valencia, CA, USA) for BEHM, cell suspension, and cell monolayers, and the Qiagen RNeasy Midi kit for neonatal heart. Briefly, the five cell monolayers from each time point were first trypsinized with $25 \%$ Trypsin-EDTA (Invitrogen Corporation, Auckland, New Zealand), pooled together, and spun down at $1500 \mathrm{rpm}$ for $5 \mathrm{~min}$ into a cell pellet. The 5 million cell suspension was also spun down at $1500 \mathrm{rpm}$ for $5 \mathrm{~min}$ into a cell pellet. The above cell pellets were then disrupted with the addition of $350 \mu \mathrm{L}$ of Buffer RNeasy Lysis Buffer (RLT). The cells were homogenized using a QIAshredder spin column (Qiagen

Inc.); the samples were added to the column and spun at maximum speed for $2 \mathrm{~min}$. The samples were then loaded into RNeasy mini columns and subjected to various washes, according to the manufacturer's protocol. The total RNA was eluted with $50 \mu \mathrm{L}$ of RNase/ DNase-free water. The BEHM constructs followed the same protocol for RNA isolation, but were homogenized and disrupted differently. Two BEHM from each group ( $<30 \mathrm{~g}$ tissue) were homogenized in $600 \mu \mathrm{L}$ of Buffer RLT using a handheld, cordless homogenizer (Fisher Scientific Co., Pittsburg, PA, USA) for $1 \mathrm{~min}$ in a $1.5-\mathrm{mL}$ microcentrifuge tube. The tissue lysate was then centrifuged at maximum speed for $3 \mathrm{~min}$ in a microcentrifuge to pellet cell debris. The supernatant was then applied to an RNeasy mini column and subjected to several washes. The total RNA was eluted with $50 \mu \mathrm{L}$ of RNase/DNase-free water. The eluted RNA samples were then pooled together for the five BEHM constructs in each group.

The neonatal heart, due to its strong collagenous fibers and weight, was processed by using an RNeasy Midi Kit. Briefly, the heart was homogenized using $2 \mathrm{~mL}$ of Buffer RLT. Next, water and Proteinase K solution (Qiagen Inc.) was added to the lysate and incubated at $55^{\circ} \mathrm{C}$ for 20 min to further break down the connective tissue, collagen, and the abundance of contractile proteins. The sample was then centrifuged at $5000 \mathrm{rpm}$ for $5 \mathrm{~min}$ to pellet the cell debris. The supernatant was then applied to an RNeasy Midi column and subjected to various washes. The total RNA was eluted using $350 \mu \mathrm{L}$ of RNase/DNase-free water.

After RNA isolation, each sample was analyzed for nucleic acid purity using the A260/A280 ratio on a spectrophotometer. Using the $260 \mathrm{~nm}$ absorbance value, the concentration of nucleic acid within each sample was determined. The samples were then stored at $-20^{\circ} \mathrm{C}$ until further processing.

\section{Reverse transcription}

cDNA was transcribed following the manufacturer's protocol for the High-Capacity cDNA Reverse 
Transcription Kit (Applied Biosystems, Foster City, CA, USA) using $0.8 \mu \mathrm{g}$ of total RNA, random primers, and RNase Inhibitor. Each sample contained $20 \mu \mathrm{L}$ of final volume. Following the manufacturer's thermal cycling conditions, the samples were first incubated at $25^{\circ} \mathrm{C}$ for $10 \mathrm{~min}, 37^{\circ} \mathrm{C}$ for $120 \mathrm{~min}, 85^{\circ} \mathrm{C}$ for $5 \mathrm{~s}$, and finally left at an infinite $4^{\circ} \mathrm{C}$ hold. Postreverse transcription, $80 \mu \mathrm{L}$ of water was added to each sample for a 1:5 dilution, and the concentration of each cDNA sample was taken using the $260 \mathrm{~nm}$ absorbance reading on a spectrophotometer.

\section{Real time reverse transcriptase PCR (RT-PCR)}

Real-time, relative quantitative PCR was performed in Biorad's iCycler detection system using predeveloped TaqMan Gene Expression Assays (Applied Biosystems). Briefly, reactions contained $2.9 \mu \mathrm{L}(100 \mathrm{ng}) \mathrm{cDNA}, 25 \mu \mathrm{L} 2 \times$ TaqMan Universal PCR Master Mix (Applied Biosystems), $2.5 \mu \mathrm{L} 20 \times$ Target Primers and Probe (Gene Expression Assays, Applied Biosystems), and $19.6 \mu \mathrm{L}$ of RNase-free water. The volume per reaction totaled $50 \mu \mathrm{L}$. Each reaction was amplified in triplicate. The target primers and probes part of the TaqMan Gene Expression Assays were inventoried, premade products. The primers of the genes of interest were chosen to be mRNA specific, spanning an exon-exon border, minimizing the interference of possible genomic DNA contamination within the samples. The relative quantification of each target gene in each group was normalized to a reference gene (endogenous control), ribosomal protein 18S. PostPCR reaction, the $\mathrm{Ct}$ value of each target gene in each condition was recorded and normalized to the endogenous control. These data were then used to determine the fold change in each gene between the different groups using the manufacturer's (BIO-RAD, Hercules, CA, USA) data analysis method, $2^{-\Delta \Delta C t}$.

\section{Histology}

Immediately following excision, the neonatal rat heart was embedded upright in optimal cutting temperature compound (O.C.T.) embedding medium within a cube-shaped cryomold and dropped in liquid nitrogen-cooled isopentane. When the BEHM was fully formed, the sutures at either end were cut with a blade, and the BEHM was placed in $4 \%$ formalin for $24 \mathrm{~h}$. After fixation, the tissues were washed in Dulbecco's phosphate buffered saline (DPBS) three times for $30 \mathrm{~min}$ each and stored in a mixture of $30 \%$ sucrose (in DPBS) and O.C.T. embedding medium overnight to allow the O.C.T. to infiltrate the small holes within the tissue. The next day, the O.C.T.- embedded tissues were frozen on dry ice. The tissues were sectioned in $9 \mu \mathrm{m}$ sections on SuperFrost Plus slides (Fisher Scientific Co.) and stored at $-80^{\circ} \mathrm{C}$ until performing histology. Hematoxylin and eosin (H\&E) staining was used for morphologic analysis of the constructs and neonatal heart.

\section{Statistical analysis}

One-way ANOVAs was used for all pairwise comparisons. Minitab V13.31 (State College, PA, USA) was used for statistical analysis.

\section{RESULTS}

\section{BEHM formation: WST-1 assay data, force test data}

During this study, three-dimensional BEHM constructs, using the layering approach, were developed (described previously). Approximately 50 BEHM constructs were made during this study, with a $100 \%$ success rate and success being defined as the formation of contractile constructs. Because the layering approach was used, the cells were able to evenly distribute throughout the gel. During formation, all the constructs developed spontaneous contractions by the third day after cell seeding, resulting in gel compaction and formation of a three-dimensional tissue construct.

At the day 4 time point, $50 \%$ formation of all the BEHM constructs was observed (Fig. 3A). The diameter average was $6.3 \pm 0.13 \mathrm{~mm}(n=5)$. Also, macroscopic spontaneous and continuous contractions throughout each construct could be seen. The constructs appeared transparent due to the high amount of fibrin gel still present. At day 7 time point, all the BEHM constructs exhibited full formation with a diameter average of $3.0 \pm 0.13 \mathrm{~mm}(n=5)$ (Fig. 3). The construct also appeared to be less transparent. All continued to exhibit uniform, macroscopic contractions. At day 10 time point, the diameter of the construct continued to decrease, reaching an average of $1.1 \pm 0.12 \mathrm{~mm}(n=5)$ (Fig. 3A). At this point, the constructs appeared nontransparent and still displayed the spontaneous contractions observed at the previous time points.

In order to validate the BEHM model, a WST-1 assay was used to determine the number of viable cells present. As a preliminary experiment, the appropriate amount of time needed to incubate the cells with the WST-1 reagent was investigated. The results validated that an overnight incubation allowed the complete metabolism of the WST-1 reagent by the cardiac cells (data not shown). The WST-1 assay results for the BEHM constructs, corresponding to the 4,7 , and day 10 time points showed no decrease in 

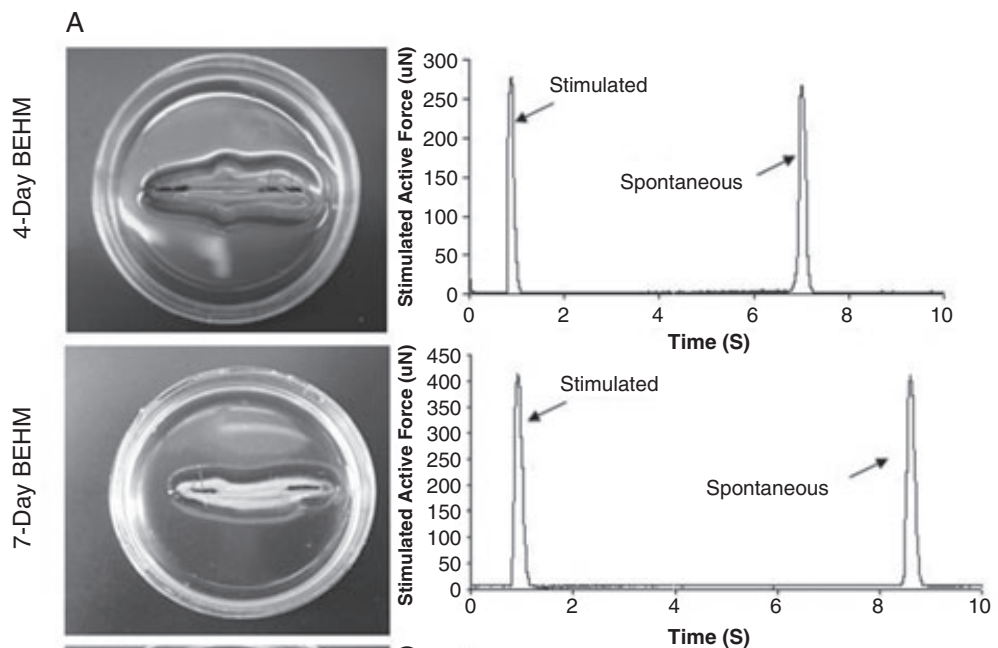
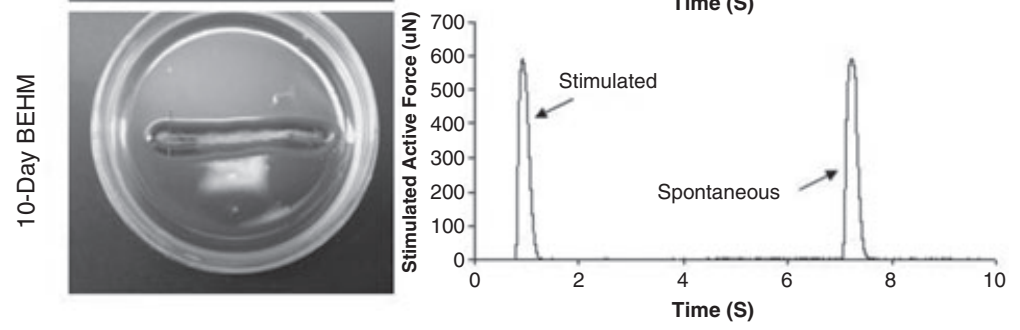

B

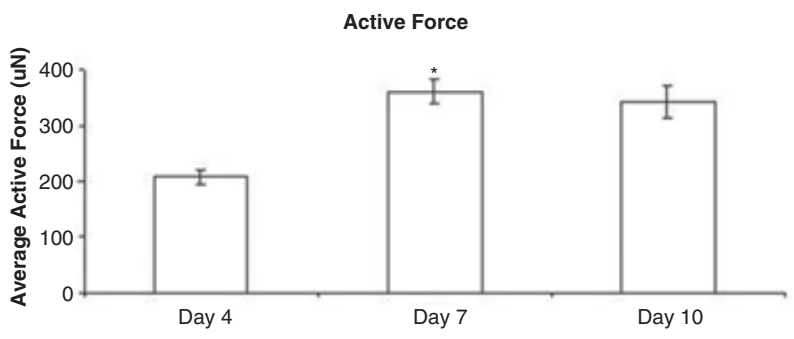

Specific Force

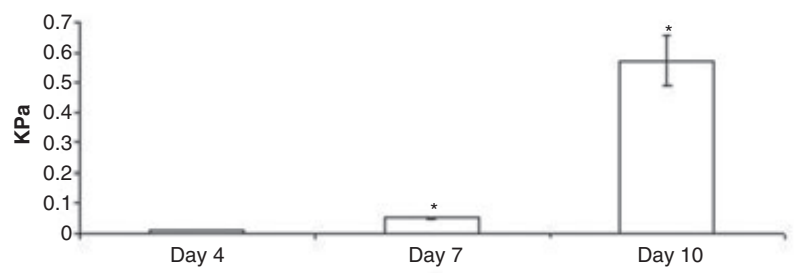

C
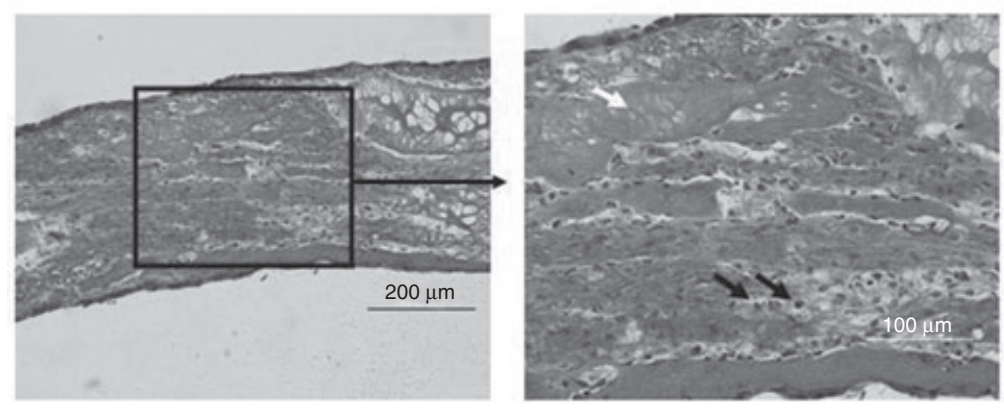

FIG. 3. Various stages of bioengineered heart muscle formation along with representative contractile and histological data are shown. (A) Spontaneous formation of BEHM at 4, 7, and 10 days postcardiac cell plating along with representative graphs of electrically stimulated active force. Several days postcell seeding, the cardiac cells began to contract and pull the fibrin gel from the plate periphery toward the middle. With each time point, the diameter of the BEHM decreased due to the degradation of the fibrin gel by cardiac cells as they build their own extracellular matrix. At each time point, we recorded the values of active force post- $25 \mathrm{~V}$ electrical stimulation. The first peak of the graphs shows the stimulated contraction, while the second shows a spontaneous contraction. (B) The active force of contraction and specific force of BEHM at each time point. For each group, $n=5$ BEHM. (C) The histology of a fully formed BEHM construct. These histology sections were H\&E stained. The black arrows point to the nuclei of cardiac cells, while the white arrow points to the fibrin gel matrix. * indicates significance with respect to day 4, for "Active Force," $P=0.0266$; for "Specific Force, $P=0.0231$ (day 7) and $P=0.0161$ (day 10). Error bars represent SD. 
cell numbers, averaging absorbencies of $0.92 \pm 0.16$ at day $4,0.87 \pm 0.03$ at day 7 , and $0.92 \pm 0.09$ at day $10(n=5)$. Based on a linear $\left(R^{2}=0.93\right)$, cardiac cell standard curve (data not shown), the absorbancy values correlated to $1.6,1.5$, and 1.6 million cells at days 4,7 , and 10 , respectively. The absorbancies for the cell monolayers at each time point also displayed constant values, providing evidence for nondecreasing cell numbers (data not shown).

Contractile performance of the BEHM constructs in response to an external, electrical stimulus was also evaluated in the current study. It was observed that the peak active force significantly increased between day 4 and day 7 time points $(208 \pm 12 \mu \mathrm{N}$ for day 4 and $361 \pm 22 \mu \mathrm{N}$ for day 7), and then plateaued for the remaining day 10 time point $(344 \pm 29 \mu \mathrm{N}, n=5$ for all groups), $P=0.0266$. Although the average peak active force remained constant, the diameter of the BEHM constructs decreased more than twofold and thus produced a higher specific force. The average specific force, however, significantly increased for day $7(0.05 \pm 0.003 \mathrm{kPa})$ and day 10 $(0.57 \pm 0.08 \mathrm{kPa})$ time points compared with the day 4 time point (Fig. 3B), $P=0.0231$ and $P=0.0161$, respectively.

After complete formation (7-10 days), the BEHM constructs were fixed and sectioned. An H\&E stain revealed seeded cardiac cells evenly distributed and surrounded by fibrin gel. Also, a noted difference in eosin color between the extracellular matrix formed by cardiac cells (lighter pink) and fibrin gel (darker red) could be seen. Sporadic patches of undegraded fibrin gel within cardiac cell clumps were also clearly visible on the slide. The outside border of the BEHM construct also looked to have an abundance of cardiac cells (Fig. 3C).

Based on the contractile, histological, and cell viability data, the functional performance of the BEHMs at all time points was confirmed.

\section{Gene expression}

RNA was extracted at each time point of the study: neonatal heart, cell suspension, 4-, 7-, 10-day cell monolayers, and 7- and 10-day BEHM. RNA extraction from the 4-day BEHM was unsuccessful using the RNeasy Midi Kit due to the high volume of fibrin gel, high weight, and low cell number. All time points, except the neonatal heart, contained a total number of 5 million cells. After RNA extraction, quantitative, real-time RT-PCR was used to characterize the gene expression of various calcium-handling proteins between the different conditions and at different time points within development. The expression of each gene was normalized to 18S RNA expression, accounting for any differences in starting amount of sample during PCR.

The total amount of RNA extracted from each sample was calculated. As expected, the total RNA extracted from the neonatal heart $(200 \mu \mathrm{g})$ drastically exceeded any other sample. Within each condition (monolayer culturing vs. BEHM), the total RNA was highest at the earlier time point $(65.1 \mu \mathrm{g}$ for 4-day monolayer vs. $16.9 \mu \mathrm{g}$ for 10 -day monolayer and $12.2 \mu \mathrm{g}$ for 7 -day BEHM vs. $9.6 \mu \mathrm{g}$ for 10-day BEHM). The monolayer culturing, overall, exhibited a higher content of total RNA versus the threedimensional BEHM culturing.

Figure 4 shows that the expression of all genes revealed a similar pattern between the conditions tested. Using the neonatal heart as a control, it was found that, as expected, this condition contained the highest gene expression for all five genes. The greatest difference in gene expression was seen between the neonatal heart control and both of the time points within the cell monolayer conditions, where gene expression had a fold change of less than 0.1 . The Ct values for MHC- $\beta$ and RyR were so high within the 7-day monolayer that the expression of these genes was taken to be zero, when compared with the neonatal heart.

The BEHM condition exhibited gene expression with a much lower difference when compared with the neonatal heart, versus comparing the monolayers to the neonatal heart. The MHC- $\beta$ expression had the lowest difference overall, with a fold change of 0.9 for day 7 time point and a fold change of 0.5 for day 10 time point. Day 7 time point for BEHM constructs exhibited a higher gene expression for all genes than day 10 time point, respectively, with fold differences of 0.2 and 0.1 for MHC- $\alpha, 0.4$ and 0.1 for SERCA 2 and 0.5 and 0.3 for both PBL and RyR.

A direct comparison of gene expression between the 7-day BEHM and monolayer, and the 10-day BEHM and monolayer was also evaluated (Fig. 5). It was determined that the expression for almost all genes is higher within the BEHM construct. MHC- $\alpha$ exhibited an almost 2600-fold increase in its expression between day 7 time points of monolayer to BEHM and a 100-fold increase between the 10-day time points. The MHC- $\beta$ and RyR gene expression at day 7 between the two culturing conditions was incomparable because there was an undetectable amount of the gene present in the 7-day BEHM construct. There was, however, a 70-fold increase in MHC- $\beta$ and a 74-fold increase in RyR going from the 10-day monolayer to 10-day BEHM. The rest of the genes displayed a similar pattern of increase in expression from the monolayer to the BEHM 
A

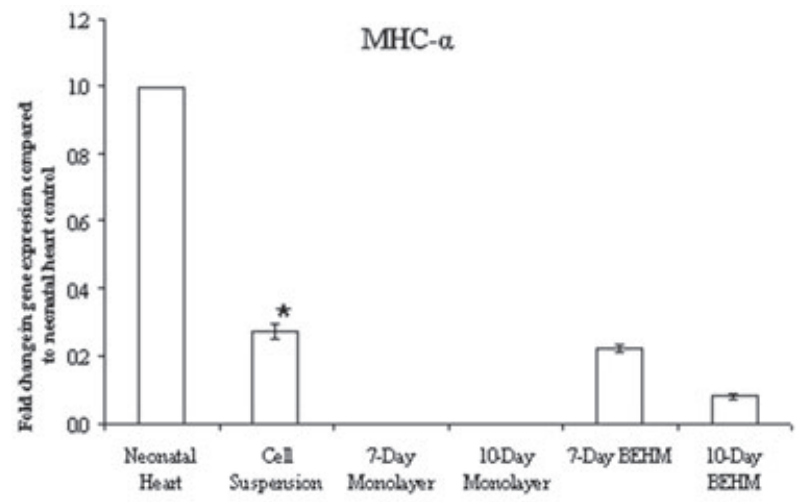

B

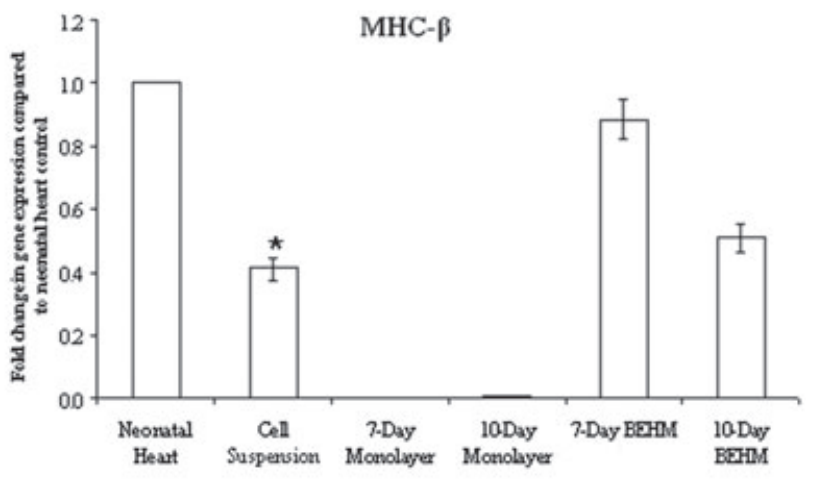

C

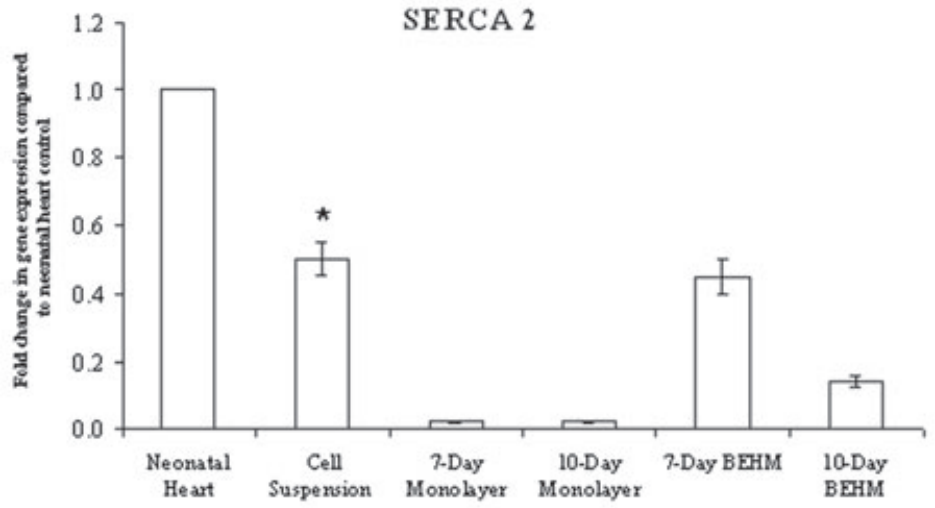

D

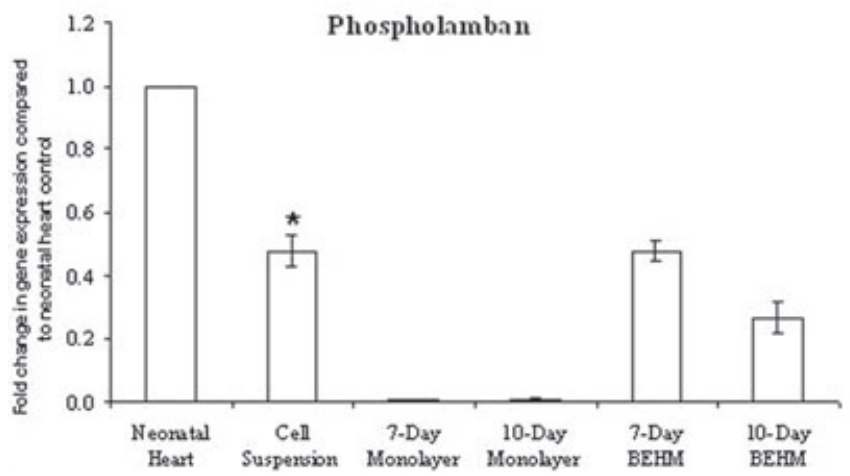

E

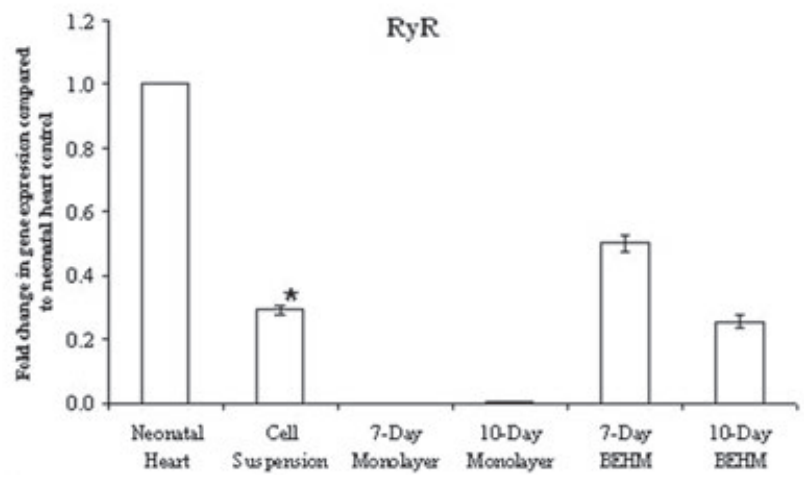

FIG. 4. Gene expression of calcium-handling genes of various conditions relative to neonatal rat heart. (A) MHC- $\alpha$, (B) MHC- $\beta$, (C) SERCA 2, (D) Phospholamban, (E) RyR. The total cell number for each condition, excluding the neonatal heart, was $5 \times 10^{6}$ cells. Real-time RT-PCR results were normalized to 18S rRNA expression at each condition and time point and then reported relative to the neonatal rat heart control sample. * indicates significance with respect to neonatal heart group, $P=8.26 \times 10^{-24}(\mathrm{MHC}-\alpha), P=4.1 \times 10^{-19}$ (MHC- $\beta$ ),$P=4.0 \times 10^{-16}$ (SERCA 2), $P=2.0 \times 10^{-15}$ (phospholamban), and $P=2.0 \times 10^{-26}$ (RyR). Error bars represent SD.

construct within each day, with a 19 -fold and sixfold increase of SERCA 2 at 7 days and 10 days, respectively, and a 158-fold and 24-fold increase of PBL at 7 days and 10 days, respectively.

Gene expressions between the neonatal heart and cell suspension approximately $2 \mathrm{~h}$ after the beginning of the cell isolation process was observed. It was found that the cells in the suspension showed gene expression for all calcium handling genes. The most expressed genes were SERCA 2 and PBL, with a fold change of 0.5 compared with that of the neonatal heart. The next highest was MHC- $\beta$ with a fold change of 0.4 , and finally MHC- $\alpha$ and RyR with a fold change of 0.3 (Fig. 4). 
A

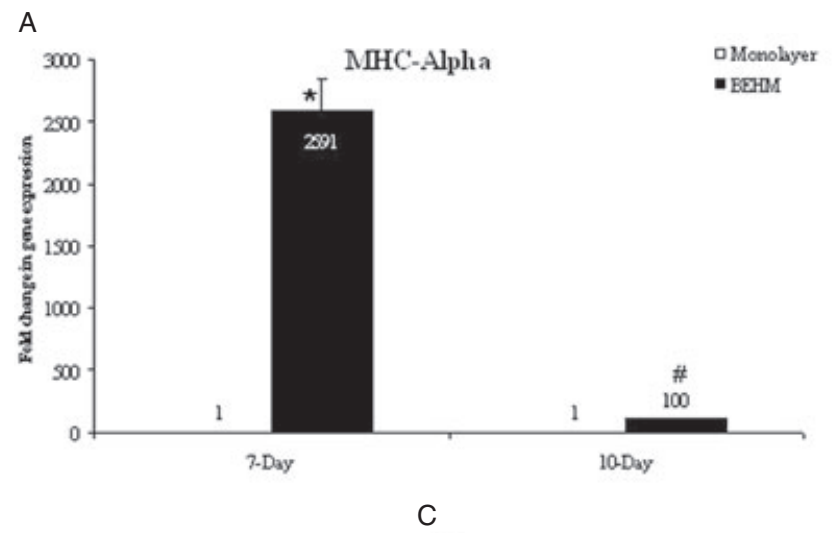

B

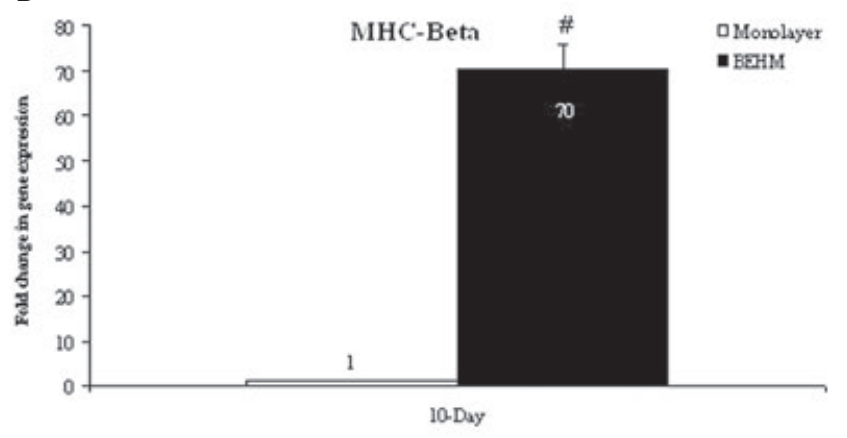

SERCA $2 \quad$ aMonolayer

- BEFM

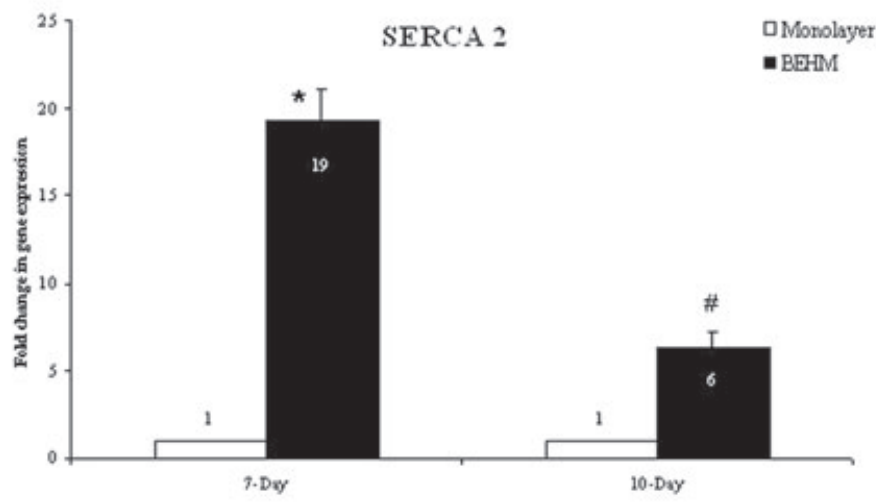

D

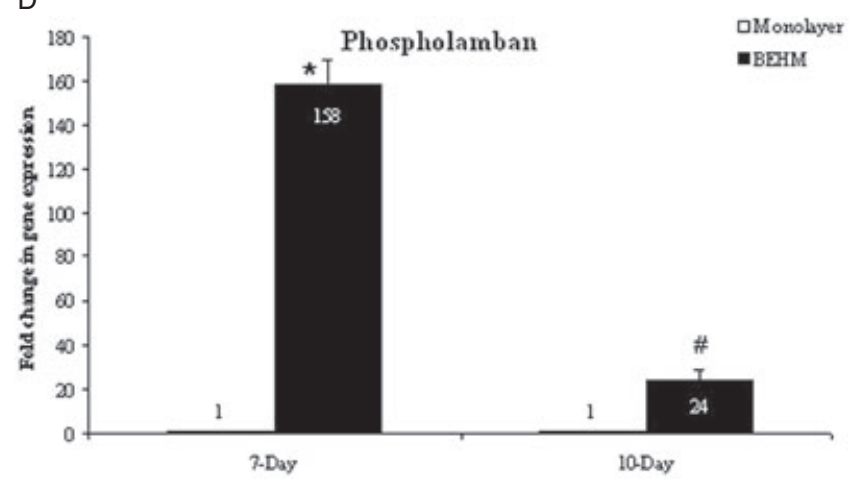

E

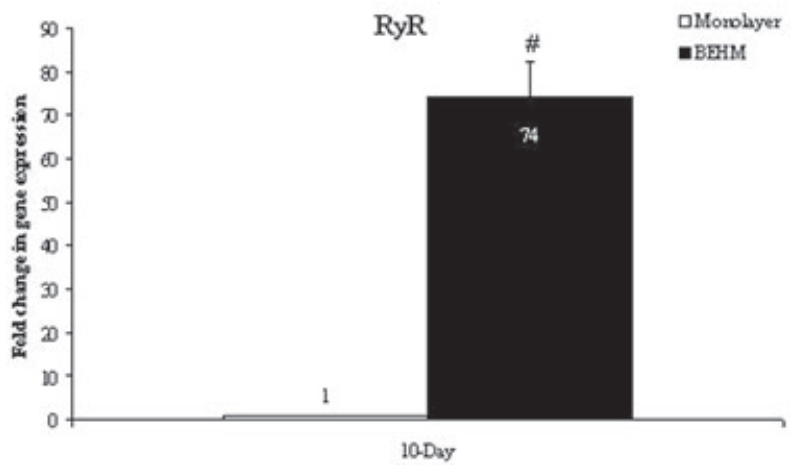

FIG. 5. Gene expression of calcium-handling genes of BEHM at days 7 and 10 time points relative to cell monolayer culturing at days 7 and 10 time points. (A) MHC- $\alpha,{ }^{*} P=1.59 \times 10^{-15},{ }^{\#} P=1.47 \times 10^{-15}$. (B) MHC- $\beta,{ }^{\#} P=2.73 \times 10^{-17}$. (C) SERCA 2, * $P=1.28 \times 10^{-15}$, ${ }^{\#} P=8.47 \times 10^{-13}$. (D) Phospholamban, * $P=5.5 \times 10^{-18}$, ${ }^{\#} P=7.55 \times 10^{-11}$. (E) RyR ${ }^{\#} P=1.4 \times 10^{-14}$. * indicates significance with respect to day 7 time point, and ${ }^{\#}$ indicates significance with respect to day 10 time point. Error bars represent SD.

The change in gene expression between the two time points during BEHM formation, at 7 and 10 days, was also analyzed. Day 7 time point was used as the comparative control. It was determined that expression of all genes was highest at day 7 time point. MHC- $\beta$ exhibited the lowest difference in expression than all other markers, 0.6 of the 7 -day BEHM construct. Approximately 0.5 -fold of gene expression was seen in phospholamban and RyR, 0.4 for MHC- $\alpha$, and 0.3 for SERCA 2 (Fig. 6).
An important observation that was extrapolated from the results is the ratio of MHC- $\beta$ to MHC- $\alpha$ and SERCA 2 to phospholamban. The approximate control ratio of the neonatal heart for MHC- $\beta$ to MHC- $\alpha$ was 1.7 . The condition that came closest to the control was the cell suspension, with a ratio of 1.5. The ratio was 1.4 for the 10-day monolayer, 1.3 for the 7-day BEHM, and 1.1 for the 10-day BEHM. Calculating the MHC- $\beta / \mathrm{MHC}-\alpha$ ratio for the 7 -day monolayer was not feasible because the presence 


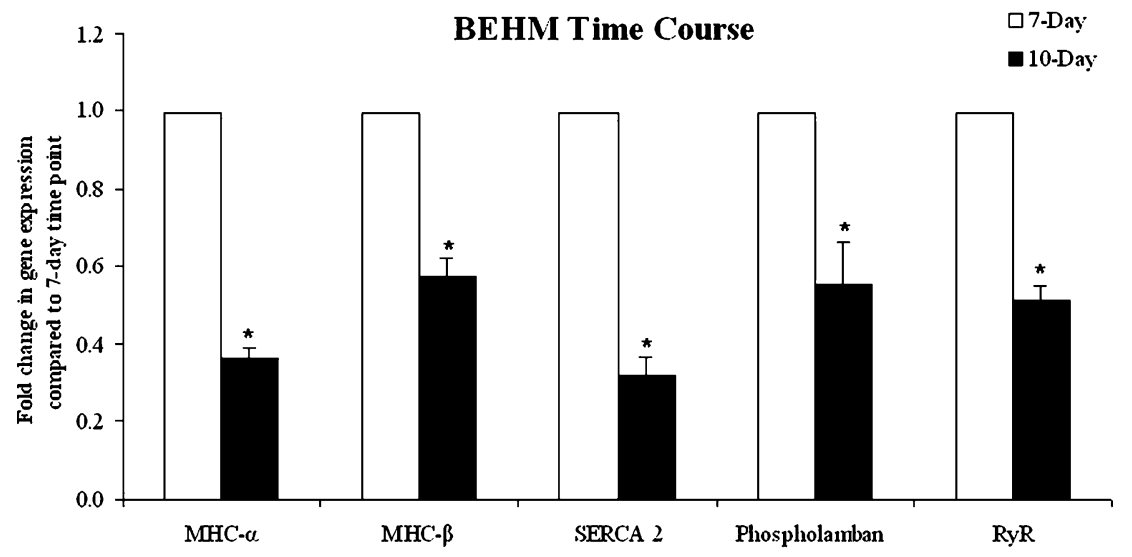

FIG. 6. Expression of calcium-handling genes during the course of formation of BEHM at 10 days relative to 7 days. * indicates significance with respect to day 7 time point, $P=2.79 \times 10^{-21}(\mathrm{MHC}-\alpha)$, $P=2.94 \times 10^{-15}(\mathrm{MHC}-\beta), P=6.8 \times 10^{-18}$ (SERCA 2), $P=1.2 \times 10^{-9}$ (phospholamban), $P=4.98 \times 10^{-17}$ (RyR). Error bars represent SD. of MHC- $\beta$ was undetectable in that condition (Fig. 7A).

The SERCA 2/PBL ratio measures the reuptake of calcium ions back into the SR after depolarization. The two markers are colocalized and work together, and it is evident in the neonatal heart ratio of 0.95 . This ratio did not fluctuate greatly between BEHM conditions, 0.96 and 1.03 at days 7 and 10 time points, respectively (Fig. 7B).

\section{DISCUSSION}

The previously developed three-dimensional heart muscle in vitro by Huang et al. demonstrated spon-

A

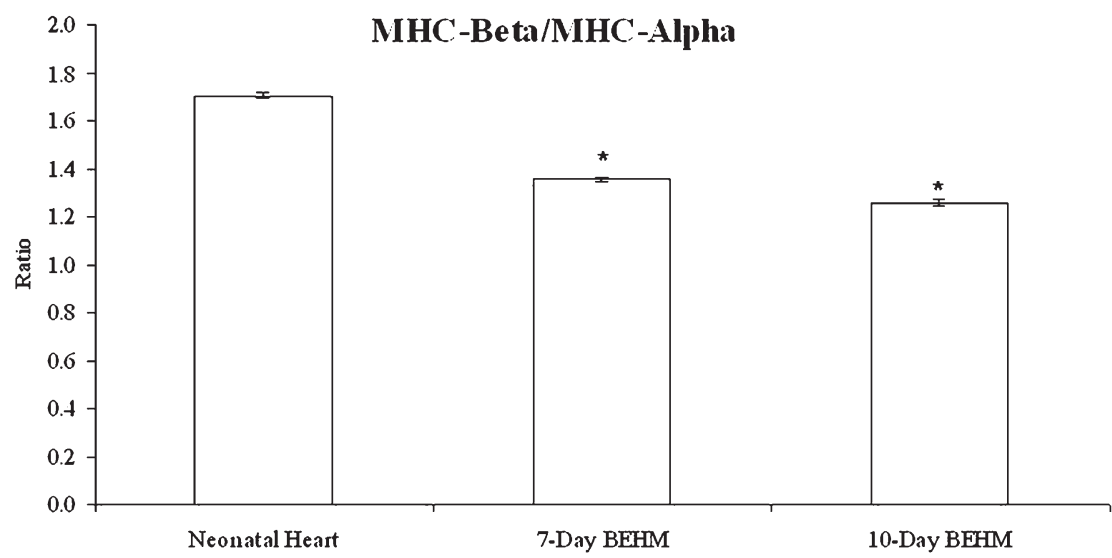

B

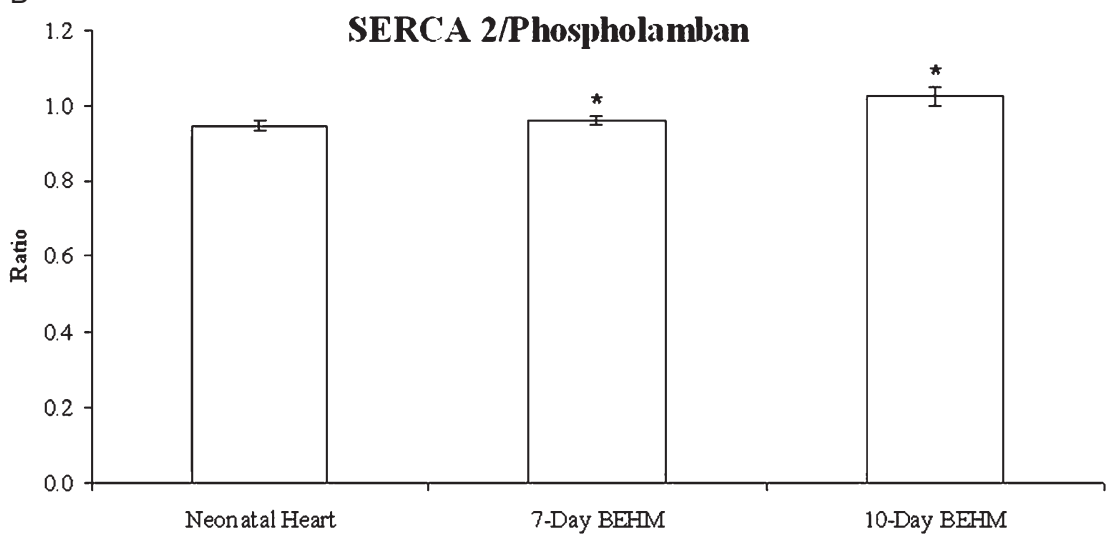

FIG. 7. Gene expression ratios of MHC- $\beta$ to MHC- $\alpha$ (A) and SERCA 2 to phospholamban (B) in the 3- to 4-day neonatal rat heart, the 7-day and 10-day BEHM. * indicates significance with respect to neonatal heart group. (A) $P=2.71 \times 10^{-20}$ (7-day BEHM), $P=6.47 \times 10^{-21}$ (10-day BEHM). (B) $P=0.0332$ (7-day BEHM), $P=3$. $2 \times 10^{-7}$ (10-day BEHM). Error bars represent SD. 
taneous and electrically stimulated contractions. In previous studies, a promising in vitro model of heart muscle or BEHM was engineered, and, in the current study, the main objective was to compare how the BEHM constructs compared biologically with native myocardial tissue. This was achieved by examining the intracellular biologic functioning of the calcium handling pathway, by comparing the gene expression of various critical biologic markers between a whole neonatal rat heart, cell suspension, monolayer culture, and BEHM.

The first objective of the current study was to reproduce the method for the formation of BEHMs. The model is fairly new and thus requires some experience to recreate. Successful recreation of a fully formed and viable BEHM construct was accomplished, and all stages of the process were completely reproducible. The formation of viable tissue constructs was supported by microscopic evaluation, WST-1 data, as well as histological and contractile performance metrics. Due to the nonchanging absorbance values, the WST-1 assay showed that the cells were thriving and not decreasing in number throughout all time points in the cell monolayers and BEHM constructs.

Histological evaluation showed numerous clumps of cells surrounded by a lighter-pink fibrin gel. As the cells began to develop their own extracellular matrix, they concomitantly degraded the fibrin gel. This was evident through an H\&E stain of a fully formed BEHM construct. The abundance of cells and their own extracellular matrix (darker pink/purple) greatly exceeded the presence of the fibrin gel (brighter pink). Because the cells were initially distributed evenly on the fibrin gel, they were able to build their own network of extracellular proteins and begin to contract in spontaneous rhythm, compacting into a three-dimensional construct from a cell monolayer.

Another test of viability and reproducibility that was performed at each time point of BEHM formation was the measure of force generated after electrical stimulation. As can be seen in Fig. 3B, the active force significantly increased between day 4 $(208 \pm 12 \mu \mathrm{N})$ and day $7(361 \pm 22 \mu \mathrm{N})$, and then leveled off by day $10(343.6 \pm 29 \mu \mathrm{N})$. This, however, was not a true measurement of the maximal force that was generated because these numbers are dependent on the diameter of each construct. Even though the peak active force stayed constant between days 7 and 10, the diameter decrease between these time points indicated a drastic increase in specific force. The specific force significantly increased from $0.007 \pm 0.002 \mathrm{kPa}$ for day 4 time point to $0.05 \pm$ $0.01 \mathrm{kPa}$ for day 7 time point and significantly increased to $0.57 \pm 0.42 \mathrm{kPa}$ for day 10 time point. These results showed a general increase in force production and further illustrated that the BEHM constructs contained viable cells integrated within a network. Collectively, the data validated the formation of functional three-dimensional BEHMs at various time points.

The next objective of this study was to determine the differences in gene expression of various calciumhandling proteins between culturing methods of neonatal cardiac cells. Because cardiac tissue engineering is a relatively new field of research and also focuses most of its efforts on developing mechanically sound models, little research investigating the biology of the bioengineered tissues has been published. First, the effect of cell isolation from a neonatal rat heart on gene expression was determined. It can be seen from Fig. 4 that all five genes investigated in this study exhibited a decrease in gene expression between a neonatal heart and a cell suspension. This may have been due to the fact that, in a cell suspension, $2 \mathrm{~h}$ into the cell isolation process, the extracellular matrix was being degraded and the cardiomyocytes had lost most of their connections to each other and thus decreased their production of calcium-handling proteins needed to maintain the rigorous and steady contractions. Even though the expression of the calcium-handling genes slightly declined between the neonatal heart and cell suspension, this result gave valuable validation for the isolation methods. The cardiac cells within this suspension were not embedded within an extracellular network and were not adhered to each other; yet they still exhibited transcription. Through these results, it was concluded that, throughout the cell isolation process, most of the cardiac cells are viable.

Next, the effects of culturing environments on cardiac cells were compared. It was important to validate the three-dimensional model against the twodimensional cell monolayer. The BEHM constructs exhibited the ability to produce active force postelectrical stimulation as well as beat spontaneously. Due to this, a fairly high expression of calciumhandling genes was expected. The difference in gene expression between the neonatal heart and BEHM constructs at both days 7 and 10 time points was lower than that of the neonatal heart and 7- and 10-day cell monolayers. This is also seen in Fig. 5, where the days 7 and 10 monolayer time points were used as controls, while comparing gene expression to that of the 7- and 10-day BEHM constructs. It is possible that the fibrin gel provided a suitable extracellular network for the cardiac cells to redevelop their role as force producers after being disrupted 
from their previous environment. Having the initial support of a fibrin gel, the cells were able to start producing their own extracellular matrix while degrading the fibrin gel and started reorganizing themselves into a three-dimensional tissue that contracted spontaneously and responded to electric stimulation as an entire unit instead of individual cells with each passing time point. Within the monolayer, the only connections that the cardiac cells had were with several neighboring cells and a culture dish that promotes adhesiveness of cells. In this culturing environment, cardiac cells may not have been able to form an appropriate matrix to be able to timely relay spontaneous contraction in order to beat as a whole tissue. Also, these cardiac cells were unable to spontaneously form into a three-dimensional model due to the attractive forces of the culture dish surface. It was concluded from these results that seeding freshly isolated cardiac cells onto a biodegradable gel, such as a fibrin gel, produced a better culturing environment for the cells to spontaneously reorganize themselves into a whole tissue and be able to exhibit the contractile properties of a normal myocardium. Generally, cultured cells, whether in a three-dimensional model or a two-dimensional monolayer, begin to produce their own extracellular matrix, contributing to the ability for contraction. The advantage of threedimensional culturing is that it gives these cells the ability to reorganize themselves further rather than be confined to one spot as a monolayer. This reorganization gives the construct, as a whole, a more organized morphology, similar to that of native myocardial tissue.

The 7-day BEHM construct and the 10-day BEHM construct were compared next, in order to determine the effects of time in culture on gene expression of calcium-handling proteins. It was found that, using day 7 time point as the relative control, that expression for all five genes exhibited a higher level at 7 days. The energy and nutrient requirements for the metabolism of cardiac cells are extremely high. An ideal culturing condition for these constructs would be a perfusion system that constantly replenishes the media with nutrients to allow the cardiac cells to function at their maximal capacity. Also, bioreactors would continuously stimulate contractions within the BEHM in order to allow the cells to adapt to the constant physical and/or electrical stimulation to make them stronger and develop into more efficient muscle tissues.

The ability for BEHM constructs to spontaneously contract led to the investigation of the role of MHC$\beta /$ MHC- $\alpha$ expression ratio. It has been documented that, within most of the cardiac development of a rat fetus, the MHC- $\beta$ isoform is strictly limited to the ventricular chamber cells, while the MHC- $\alpha$ isoform is highly expressed in the atrial cells $(19,24)$. Later in fetal development and close to birth, MHC- $\alpha$ transcription begins to take place within the ventricular cardiomyocytes and by day 7 post birth and almost all of the MHC- $\beta$ isoform is replaced by MHC- $\alpha$ isoform (24). During human development, however, MHC- $\beta$ is the predominant isoform expressed in ventricular myocytes in both the fetal and adult life, while the MHC- $\alpha$ isoform is expressed in the atrium $(25,26)$.

In the results of the current study, it was found that the ratio of MHC- $\beta$ to MHC- $\alpha$ was at 1.7 for the neonatal heart. It is believed that this ratio is so high because the heart (at days 3 to 4 postbirth) has not yet had enough time to fully replace all the MHC- $\beta$ with the MHC- $\alpha$ isoform. Both of these isoforms were present at this time because the process was well underway toward postnatal development. There was a slight decrease in this ratio during the 7- and 10-day BEHM development. If the neonatal heart had not been disrupted, the most likely scenario would have been the complete replacement of MHC- $\beta$ with MHC- $\alpha$. However, because the cells were isolated and subsequently cultured in vitro, they were not able to take on their end-stage role as fasttwitch, MHC- $\alpha$ cardiomyocytes. It would be interesting to observe the ratio of MHC- $\beta$ to MHC- $\alpha$ in BEHM constructs cultured for longer than 10 days. In that case, a comparison of the ratio to a native adult myocardium would be useful to see if the construct develops an adult phenotype of contractile proteins.

As mentioned in the introduction, SERCA 2 and PBL are colocalized with each other. Also, the phosphorylation of PBL leads to the enhancement of SERCA 2 by increasing its affinity to calcium ions. It has been reported that, for an adult rodent heart, the SERCA 2/PBL ratio in the ventricle varies between 1.0 and $1.9(27,28)$. The SERCA 2/PBL ratio of the neonatal heart was 0.95 . This ratio did not fluctuate much between the other conditions. These results provided evidence that the genes responsible for calcium reuptake were consistently and concomitantly expressed.

\section{CONCLUSIONS}

A successful comparison of gene expressions of five calcium-handling proteins between a neonatal heart and various culturing conditions was achieved. It was concluded that culturing the cells in a threedimensional environment produces tissues that more closely resemble native cardiac tissue (29-31). There still needs to be a lot more research done in order to 
develop the perfect culturing conditions which will provide the correct and adequate amount of nutrients to each cell. For now, the current model described is a good building block for development of tissues that will one day be used on patients with end-stage heart failure.

Acknowledgment: This work was supported by funds from the Section of Cardiac Surgery at the University of Michigan.

\section{REFERENCES}

1. Fuchs JR, Nasseri BA, Vacanti JP. Tissue engineering: a 21st century solution to surgical reconstruction. Ann Thorac Surg 2001;72:577-91.

2. Lysaght MJ, Reyes J. The growth of tissue engineering. Tissue Eng 2001;7:485-93.

3. Goldstein DJ, Smego D, Michler RE. Surgical aspects of congestive heart failure. Heart Fail Rev 2006;11:171-92.

4. Carrier L, Papadaki M, Rupnick M, et al. Cardiac tissue engineering: cell seeding, cultivation parameters, and tissue construct characterization. Biotechnol Bioeng 1999;64:580-9.

5. Leor J, Aboulafia-Etzion S, Dar A, et al. Bioengineered cardiac grafts: a new approach to repair the infarcted myocardium? Circulation 2000;102(Suppl 3):III56-61.

6. Li R, Yau TM, Weisel RD, et al. Construction of a bioengineered cardiac graft. J Thorac Cardiovasc Surg 2000;119:36875 .

7. Shapiro L, Cohen S. Novel alginate sponges for cell culture and transplantation. Biomaterials 1997;18:583-90.

8. Huang YC, Khait L, Birla RK. Contractile three-dimensional bioengineered heart muscle for myocardial regeneration. J Biomed Mater Res A 2007:80:719-31.

9. Laver DR. Regulation of ryanodine receptors from skeletal and cardiac muscle during rest and excitation. Clin Exp Pharmacol Physiol 2006;33:1107-13.

10. Tada M, Toyofuku T. SR Ca(2+)-ATPase/phospholamban in cardiomyocyte function. $J$ Card Fail 1996;2(Suppl):S77-85.

11. Fujii J, Lytton J, Tada M, MacLennan DH. Rabbit cardiac and slow-twitch muscle express the same phospholamban gene. FEBS Lett 1988;227:51-5.

12. James P, Inui M, Tada M, Chiesi M, Carafoli E. Nature and site of phospholamban regulation of the $\mathrm{Ca} 2+$ pump of sarcoplasmic reticulum. Nature 1989;342:90-2.

13. Kirchberger MA, Tada M. Effects of adenosine $3^{\prime}: 5^{\prime}$ monophosphate-dependent protein kinase on sarcoplasmic reticulum isolated from cardiac and slow and fast contracting skeletal muscles. J Biol Chem 1976;251:725-9.

14. Tada M, Kirchberger MA, Repke DI, Katz AM. The stimulation of calcium transport in cardiac sarcoplasmic reticulum by adenosine $3^{\prime}: 5^{\prime}$-monophosphate-dependent protein kinase. J Biol Chem 1974;249:6174-80.

15. Harrington WF, Rodgers ME. Myosin. Annu Rev Biochem 1984;53:35-73.

16. Eisenberg E, Greene LE. The relation of muscle biochemistry to muscle physiology. Annu Rev Physiol 1980;42:293-309.

17. Swynghedauw B. Developmental and functional adaptation of contractile proteins in cardiac and skeletal muscles. Physiol Rev 1986;66:710-71.

18. Hoh JF, McGrath PA, Hale PT. Electrophoretic analysis of multiple forms of rat cardiac myosin: effects of hypophysectomy and thyroxine replacement. J Mol Cell Cardiol 1978;10:1053-76.

19. Morkin E. Control of cardiac myosin heavy chain gene expression. Microsc Res Tech 2000;50:522-31.

20. Boluyt M, Zheng JS, Younes A, et al. Rapamycin inhibits alpha 1-adrenergic receptor-stimulated cardiac myocyte hypertrophy but not activation of hypertrophy-associated genes. Evidence for involvement of p70 S6 kinase. Circ Res 1997;81:17686.

21. Dennis RG, Kosnik PE2 ${ }^{\text {nd }}$. Excitability and isometric contractile properties of mammalian skeletal muscle constructs engineered in vitro. In Vitro Cell Dev Biol Anim 2000;36:327-35.

22. Huang YC, Dennis RG, Larkin L, Baar K. Rapid formation of functional muscle in vitro using fibrin gels. J Appl Physiol 2005;98:706-13.

23. Baar K, Birla R, Boluyt MO, Borschel GH, Arruda EM, Dennis RG. Self-organization of rat cardiac cells into contractile 3-D cardiac tissue. FASEB J 2005;19:275-7.

24. Lyons GE, Schiaffino S, Sassoon D, Barton P, Buckingham M. Developmental regulation of myosin gene expression in mouse cardiac muscle. J Cell Biol 1990;111:2427-36.

25. Kurabayashi M, Tsuchimochi H, Komuro I, Takaku F, Yazaki Y. Molecular cloning and characterization of human cardiac alpha- and beta-form myosin heavy chain complementary DNA clones. Regulation of expression during development and pressure overload in human atrium. J Clin Invest 1988; 82:524-31.

26. Everett AW. Isomyosin expression in human heart in early pre- and post-natal life. J Mol Cell Cardiol 1986;18:607-15.

27. Ojamaa K, Kenessey A, Klein I. Thyroid hormone regulation of phospholamban phosphorylation in the rat heart. Endocrinology 2000;141:2139-44.

28. Koss KL, Grupp IL, Kranias EG. The relative phospholamban and SERCA2 ratio: a critical determinant of myocardial contractility. Basic Res Cardiol 1997;92(Suppl 1):17-24.

29. Petersen MC, Lazar J, Jacob HJ, Wakatsuki T. Tissue engineering: a new frontier in physiological genomics. Physiol Genomics 2007;32:28-32.

30. Hecker L, Birla RK. Engineering the heart piece by piece: state of the art in cardiac tissue engineering. Regen Med 2007;2:125-44.

31. Kofidis T, Balsam L, de Bruin J, Robbins RC. Distinct cell-tofiber junctions are critical for establishment of cardiotypical phenotype in a 3D bioartificial environment. Med Eng Phys 2004;26:157-63. 